\section{Emergent Neurovascular Imaging: A Necessity for the Work-Up of Minor Stroke and TIA}

(D)S.B. Coutts and (D) M. Goyal

M ost ischemic strokes are judged "minor" and nondisabling. ${ }^{1}$ Symptoms being too mild or minor is the most common reason for withholding thrombolysis. ${ }^{2}$ However, this seemingly mild presentation is misleading because the prognosis is not benign, with up to one-third of patients having died or being disabled at follow-up. ${ }^{2}$

\section{Natural History and Imaging Findings}

We can identify a subset of patients with minor stroke who are at the highest risk of poor outcome by using noninvasive CT angiography. Patients with minor stroke with documented intracranial arterial occlusion are at particularly high risk of early neurologic deterioration and disability. ${ }^{3-5}$ This is true whether the occlusion is proximal or distal ${ }^{6}$ or whether the initial deficits have completely resolved. ${ }^{7}$ Even in the absence of neurologic deterioration, these patients are at higher risk of disability than those with minor stroke without intracranial occlusion. This presumably is from a mechanism such as silent infarct growth. ${ }^{8}$ These patients represent at least $10 \%$ of those with minor stroke, ${ }^{4}$ and this number is likely higher with better imaging techniques, such as multiphase CTA (mCTA) ${ }^{9}$ and perfusion, helping to identify more distal occlusions.

\section{Why Image Minor Stroke?}

Why bother identifying patients with minor stroke with intracranial occlusion? We believe that understanding disease pathophysiology is the first step in the treatment of these patients. Stroke is a plumbing disorder, so better identification of the problem and its exact location would result in better diagnosis and treatment. Few stroke physicians, particularly in the era of endovascular treatment ${ }^{10,11}$ of stroke, would disagree that early vascular imaging with CTA is crucial for the early management of patients with moderate-to-severe stroke. We believe that the same is true for patients with minor cerebrovascular events (TIA and minor stroke).

\section{What Imaging Technique to Use}

In most institutions, imaging of minor stroke is best completed by using CT, CTA and MCTA, or CT perfusion. In some parts of the world, MR imaging is easily performed, but vascular imaging is still required. DWI is useful in confirming that the patient actually has ischemia, but for many patients, the absence of a DWI lesion will not change the management plan. ${ }^{12}$ The management plan is driven by finding an intracranial occlusion or an intracranial or extracranial stenotic lesion, thus making urgent vascular imaging a key part of the initial work-up.

http://dx.doi.org/10.3174/ajnr.A4553

\section{Triage and Management Decisions}

At our institution, for several years, all patients with suspected stroke symptoms undergo a plain head CT, CTA, and mCTA. Clinical trials are being performed in patients with intracranial occlusion. ${ }^{13}$ Ideally, patients would be randomized in such a trial. In the absence of an available trial, a decision can be made on an individual patient basis as to whether to perform thrombolysis or to use dual antiplatelet therapy, for example. ${ }^{14}$ Further stroke etiology is an important driver of outcome because it strongly influences the early risk of recurrence with as much as $50 \%$ of early recurrences being due to large-artery disease. ${ }^{15}$ In addition, recognizing of the magnitude of the problem, better understanding its natural history, and understanding the underlying pathophysiology will trigger new solutions for improving outcomes. Thus, it makes sense to image both the intracranial and extracranial circulation simultaneously in the emergency department. This allows urgent treatment decisions to be made quickly and a treatment plan to be implemented.

We have safely used findings from urgent CTA to triage patients who need to be seen that evening versus those than can be seen in the clinic the next day. Patients with high-risk vascular lesions are seen that night and admitted to the hospital, and those whose symptoms have resolved and have normal CTA findings are usually sent home. From an overall expense perspective, we believe that urgent CTA does not add additional cost because these patients require neurovascular imaging anyway (even if performed in a nonemergent fashion). Additionally, by standardizing the protocol for acute stroke work-up across major and minor stroke, we have been able to improve efficiency at all levels, including image acquisition, postprocessing, and interpretation.

In the near future, all patients with minor stroke and TIA should have emergent neurovascular imaging. This is a necessary step toward improving outcomes in these patients.

Disclosures: Mayank Goyal—RELATED: Other: GE Healthcare, Comments: licensing agreement for Systems of Stroke Diagnosis (patent pending); UNRELATED: Consultancy: Covidien, Comments: for teaching engagements; for design and conduct of the Solitaire With the Intention For Thrombectomy as PRIMary Endovascular Treatment trial; Grants/Grants Pending: Covidien, ${ }^{*}$ Comments: part funding of the Endovascular Treatment for Small Core and Anterior Circulation Proximal Occlusion with Emphasis on Minimizing CT to Recanalization Times trial. *Money paid to the institution.

\section{REFERENCES}

1. Reeves M, Khoury J, Alwell K, et al. Distribution of National Institutes of Health Stroke Scale in the Cincinnati/Northern Kentucky Stroke Study. Stroke 2013;44:3211-13 CrossRef Medline

2. Smith EE, Fonarow GC, Reeves MJ, et al. Outcomes in mild or rapidly improving stroke not treated with intravenous recombinant tissue-type plasminogen activator: findings from Get With The Guidelines-Stroke. Stroke 2011;42:3110-15 CrossRef Medline

3. Smith EE, Abdullah AR, Petkovska I, et al. Poor outcomes in patients who do not receive intravenous tissue plasminogen activator because of mild or improving ischemic stroke. Stroke 2005;36:2497-99 CrossRef Medline

4. Coutts SB, Modi J, Patel SK, et al; Calgary Stroke Program. CT/CT angiography and MRI findings predict recurrent stroke after transient ischemic attack and minor stroke: results of the prospective CATCH study. Stroke 2012;43:1013-17 CrossRef Medline 
5. Coutts SB, Modi J, Patel SK, et al. What causes disability after transient ischemic attack and minor stroke? Results from the CT and MRI in the Triage of TIA and Minor Cerebrovascular Events to Identify High Risk Patients (CATCH) Study. Stroke 2012;43: 3018-22 CrossRef Medline

6. Dubuc V, Singh D, Modi J, et al. TIA and minor stroke patients with intracranial occlusions in both proximal and distal vessels are most at risk for symptom progression. Cerebrovasc Dis 2014;38:389-90 CrossRef Medline

7. Poisson SN, Nguyen-Huynh MN, Johnston SC, et al. Intracranial large vessel occlusion as a predictor of decline in functional status after transient ischemic attack. Stroke 2011;42:44-47 CrossRef Medline

8. Asdaghi N, Hill MD, Coulter JI, et al. Perfusion MR predicts outcome in high-risk transient ischemic attack/minor stroke: a derivation-validation study. Stroke 2013;44:2486-92 CrossRef Medline

9. Menon BK, d'Esterre CD, Qazi E, et al. Multiphase CT angiography: a new tool for the imaging triage of patients with acute ischemic stroke. Neuroradiology 2015;275:510-20 CrossRef Medline
10. Goyal M, Demchuk AM, Menon BK, et al; ESCAPE Trial Investigators. Randomized assessment of rapid endovascular treatment of ischemic stroke. $N$ Engl J Med 2015;372:1019-30 CrossRef Medline

11. Berkhemer OA, Fransen PS, Beumer D, et al. A randomized trial of intraarterial treatment for acute ischemic stroke. NEngl J Med 2015; 372:11-20 CrossRef Medline

12. Coutts SB, Cucchiara B. Stroke risk after TIA: DWI is only part of the answer. Neurology 2013;80:1914-15 CrossRef Medline

13. ClinicalTrials.gov. A Randomized Controlled Trial of TNK-tPA Versus Standard of Care for Minor Ischemic Stroke With Proven Occlusion (TEMPO-2). https://clinicaltrials.gov/ct2/show/NCT02398656? term $=$ TEMPO-2\&rank=1. Accessed July 15, 2015

14. Wang Y, Wang Y, Zhao X, et al; CHANCE Investigators. Clopidogrel with aspirin in acute minor stroke or transient ischemic attack. N Engl J Med 2013;369:11-19 CrossRef Medline

15. Lovett JK, Coull AJ, Rothwell PM. Early risk of recurrence by subtype of ischemic stroke in population-based incidence studies. Neurology 2004;62:569-73 CrossRef Medline 